\title{
The use of doxazosin before adrenalectomy for pheochromocytoma: is the duration related to intraoperative hemodynamics and postoperative complications?
}

\author{
Hao Kong ${ }^{1} \cdot \mathrm{Nan} \mathrm{Li}^{1} \cdot \mathrm{Jie} \mathrm{Tian}^{2,3,4}$ ( Zhengqing $\mathrm{BaO}^{2,3,4} \cdot \mathrm{Lu} \mathrm{Liu}^{6} \cdot \mathrm{Kai} \mathrm{Wu}^{6} \cdot \mathrm{Ying} \mathrm{Gao}^{6} \cdot \mathrm{Bo} \mathrm{Jin}^{7} \cdot$ Zheng Zhang $^{2,3,4}$. \\ Dong Fang $2,3,4,5$. Junqing Zhang ${ }^{6} \cdot$ Liqun Zhou $^{2,3,4}$
}

Received: 3 April 2020 / Accepted: 10 June 2020 / Published online: 3 July 2020

(c) The Author(s) 2020

\begin{abstract}
Purpose No conclusion exists for the optimum duration of preoperative administration of doxazosin (DOX) before adrenalectomy for pheochromocytoma. The purpose of this study is to investigate whether perioperative hemodynamics and postoperative outcomes are related to the duration of DOX administration.

Methods In total, 132 patients managed preoperatively with single $\alpha$-receptor blocker DOX were enrolled. All patients underwent adrenalectomy for pheochromocytoma in the Department of Urology, Peking University First Hospital, between January 2001 and July 2019. Patients were divided into three groups based on the duration of preoperative administration of DOX: group A ( $\leq 14$ days), group B (15-30 days), and group C ( $>30$ days). Patient and tumor characteristics, intraoperative hemodynamics, and postoperative outcomes were recorded and compared.

Results These patients included 57 men and 75 women, with an average age of 48 years. Clinical characteristics, preoperative hemodynamics, medicine management and surgical approaches were comparable between the three groups. Among the three groups, we found that group C ( $>30$ days) had the lowest intraoperative minimum heart rate [group A vs. group B vs. group $\mathrm{C}=60$ (52-67) vs. 59 (50-61) vs. 51.5 (50-58.75), $p=0.024$ ] and highest risk of postoperative hypotension requiring vasopressor support [group A vs. group B vs. group C $=14$ (20.3\%) vs. 12 (27.9\%) vs. $10(50.0 \%), p=0.032$ ].

Conclusion The current study indicated that preoperative management of pheochromocytoma with single $\alpha$-receptor blocker DOX for more than 30 days after final dose adjustment might lead to intraoperative bradycardia and more postoperative hypotension requiring vasopressor support. Thus, our study does not support long-term (over 30 days) preoperative administration of pheochromocytoma with single $\alpha$-receptor blocker DOX in the final dose.
\end{abstract}

Keywords Doxazosin (DOX) $\cdot$ Pheochromocytoma $\cdot$ Duration $\cdot$ Hemodynamic $\cdot$ Hypotension $\cdot$ Bradycardia

Hao Kong, Nan Li and Jie Tian contributed equally.

Zheng Zhang

doczhz@aliyun.com

$\triangle$ Dong Fang

fdmailbox@126.com

$\triangle$ Junqing Zhang

13611167278@139.com

1 Department of Anaesthesiology and Critical Care Medicine, Peking University First Hospital, No. 8 Xishiku Street, Xicheng District, Beijing 100034, China

2 Department of Urology, Peking University First Hospital, No. 8 Xishiku Street, Xicheng District, Beijing 100034, China
Institute of Urology, Peking University, No. 8 Xishiku Street, Xicheng District, Beijing 100034, China

4 National Urological Cancer Center, No. 8 Xishiku Street, Xicheng District, Beijing 100034, China

5 Andrology Center, Peking University First Hospital, No. 8 Xishiku Street, Xicheng District, Beijing 100034, China

6 Department of Endocrinology, Peking University First Hospital, No. 8 Xishiku Street, Xicheng District, Beijing 100034, China

7 Department of Clinical Laboratory, Peking University First Hospital, No. 8 Xishiku Street, Xicheng District, Beijing 100034, China 


\section{Introduction}

Pheochromocytomas is a rare neuroendocrine vascular tumor with a low incidence of 0.8 per 100,000 people years [1]. Nearly $80-85 \%$ of pheochromocytomas arise from chromaffin cells in the adrenal medulla [2]. Because the release of catecholamine by pheochromocytomas differs among patients, a series of various clinical manifestations might present, typically including hypertension, diaphoresis, and tachycardia [3]. Currently, surgical resection is the only available curative treatment [4]. However, intraoperative tumor handling and accidental squeezing of the tumor can cause unpredictable and extensive catecholamine release into circulation [5]. This surgery leads to dangerous intraoperative hemodynamic instability changes, including rapid and severe blood pressure fluctuations that significantly increase the risk of major morbidity [6]. Preoperative hypotensive drugs could help decrease operative mortality and perioperative complications in patients undergoing pheochromocytoma removal from $45 \%$ to $<1 \%$ and $69 \%$ to $3 \%$, respectively $[7,8]$. The Clinical Practice Guidelines of the Endocrine Society in the United States of America recommend that all patients with hormonally functional pheochromocytoma receive preoperative $\alpha$-adrenergic receptor blockers for 7-14 days. However, no distinction is made between selective and nonselective $\alpha$-blockers, and it is unclear whether selective $\alpha$-blockers require more extended preoperative medication management.

It should be noted that the current duration of preoperative medicine administration is based on the clinical experience of doctors and not high-quality evidence-based research [9]. Although nonselective adrenergic blockers (phenoxybenzamine, PXB) are the most common protocol [10], retrospective studies demonstrated that $\alpha 1$-selective adrenergic receptor blockers (doxazosin, DOX) lead to fewer $\alpha 2$-driven side effects and could avoid prolonged postoperative hypotension [1]. Our previous study demonstrated no additional benefits of long-term (over 30 days) preoperative administration of PXB [11]. However, the optimal duration of preoperative use of DOX is debated. Therefore, this study aimed to investigate whether perioperative hemodynamics and postoperative outcomes are related to the duration of single $\alpha$-receptor blocker DOX.

\section{Patients and methods}

Data were reviewed from patients who underwent adrenalectomy for pheochromocytoma in the Department of Urology, Peking University First Hospital, between January 2001 and July 2019. A total of 174 patients received
DOX before surgery and were initially considered for this study, 42 of whom were excluded, including 12 patients with bilateral or multiple pheochromocytomas, 21 patients with incomplete data, 7 patients with tumor recurrence and 2 patients with extra-adrenal tumors. Finally, after filtering, 132 patients were enrolled.

All patient medical records and imaging data were reviewed to collect information on patient demographics, blood pressure, heart rate (HR), surgical methods, tumor size, and tumor laterality. Preoperative maximum systolic and diastolic blood pressure (SBP and DBP) and HR were defined as the largest values obtained prior to initiation of surgical treatment. Additionally, we defined the SBP, DBP, and HR values 1 day before the operation as the preoperative SBP, DBP, and HR.

All patients received at least one catecholamine test before surgery, such as adrenaline, norepinephrine, dopamine for plasma or urinary, or vanillylmandelic acid. We have tested metanephrines for patients with suspected pheochromocytoma since 2016. Therefore, only 25 of 132 patients in this study underwent metanephrine testing. All patients' biochemical test values were considered to be positive and beyond the upper limit of the normal range.

All patients received single selective $\alpha$-blockade DOX for preoperative medical preparation. The initial dosage of DOX was $4 \mathrm{mg}$ orally once daily. Clinicians can increase or decrease the dose of DOX based on the patient's daily blood pressure fluctuations. Eventually, we stabilized the patient's blood pressure below 140/80 $\mathrm{mmHg}$, and with the peripheral circulation changes, the limbs were warm to the touch. Patients can be slightly tolerant to the side effects of doxazosin, such as orthostatic hypotension and nasal stiffness [2]. After $\alpha$-blockade DOX was achieved, a $\beta$-blocker was added for additional heart rate control when necessary. Other hypertensive drugs such as angiotensin-converting enzyme inhibitors (ACEIs), angiotensin receptor blockers (ARBs), or calcium channel blockers (CCBs) were also considered when required. All patients were prepared for surgery with 1-2 L intravenous saline infusion in the evening before surgery.

After preoperative management with single $\alpha$-receptor blocker doxazosin, all patients underwent adrenalectomy under general anesthesia by experienced surgeons. All patients received an arterial line for blood pressure monitoring. Blood pressure data were collected from anesthesia records. The intraoperative hemodynamic instability measurements collected included (1) maximum and minimum SBP and DBP; (2) number of patients with high SBP (criteria included $\geq 160 \mathrm{mmHg}, 160-179 \mathrm{mmHg}$, $\geq 180 \mathrm{mmHg}, \quad 180-199 \mathrm{mmHg}, \quad \geq 200 \mathrm{mmHg}$, 200-219 $\mathrm{mmHg}$, and $\geq 220 \mathrm{mmHg}$ ); (3) $\mathrm{SBP}>130 \%$ of basic SBP; (4) SBP $<80 \mathrm{mmHg}$; (5) $\mathrm{SBP}<70 \%$ of basic SBP; (6) maximum and minimum HR; (7) HR > 120 bpm; 
(8) mean arterial pressure (MAP) $<60 \mathrm{mmHg}$; (9) number of patients with SBP $\geq 200$ and/or MAP $<60 \mathrm{mmHg}$; (10) $\Delta \mathrm{SBP}=\mathrm{SBP}_{\text {max }}-\mathrm{SBP}_{\text {min }} ;(11) \Delta \mathrm{DBP}=\mathrm{DBP}_{\text {max }}-\mathrm{DBP}-$ min; and (12) $\Delta \mathrm{HR}=\mathrm{HR}_{\max }-\mathrm{HR}_{\min }$. Basal SBP was defined as the patient's SBP 1 day before surgery.

The duration of preoperative management, referred to as the duration of the final dose (DFD), ranged from the time of final dose adjustment to surgery. According to the DFD, 132 patients were divided into three groups: group A ( $\leq 14$ days), group B (15-30 days), and group $\mathrm{C}$ (>30 days). Patient and tumor characteristics, intraoperative hemodynamics, and postoperative outcomes were recorded and compared among the three groups.

The primary outcome was intraoperative hemodynamic instability, and the secondary endpoint was postoperative complications. Complications directly related to hemodynamic stability included new arrhythmia and postoperative hypotension and use of vasopressor, and those not directly related to hemodynamic stability included pulmonary complications, postoperative stroke, wound infection, intestinal obstruction, urinary tract infection, acute liver injury after the operation, postoperative acute kidney injury, venous thrombosis, and hypoglycemia. The criteria of the Japan Clinical Oncology Group were used to evaluate the severity of the complications [12].

\section{Statistical analysis}

Statistical analysis was performed using SPSS version 20.0 (IBM Corp, Armonk, NY, USA), and statistical significance was set at $p<0.05$. Pearson's test and the chisquare test were used to test the distribution of categorical variables, and the $F$ test was applied for continuous variables. The Kruskal-Wallis test was used for non-normally distributed variables.

\section{Results}

\section{Patient and tumor characteristics}

A total of 132 patients were enrolled in this study, including 57 men and 75 women, with an average age of 48 years. All patients were divided into three groups: 69 cases in group A ( $\leq 14$ days), 43 cases in group B (15-30 days) and 20 cases in group $\mathrm{C}$ (>30 days). The age, sex, body mass index (BMI), tumor laterality, tumor size, biochemically positive status and perioperative drug management in the three groups were comparable, as shown in Table 1 . We found no significant difference in preoperative hemodynamics.

\section{Intraoperative hemodynamics and postoperative outcomes}

The detailed data of intraoperative hemodynamics are shown in Table 2. Among the three groups, we found no significant difference in intraoperative minimum SBP $(p=0.260)$ or $\operatorname{DBP}(p=0.300)$, intraoperative maximum SBP $(p=0.222)$ or $\operatorname{DBP}(p=0.091)$, intraoperative maximum HR $(p=0.756)$, $\Delta \mathrm{SBP}(p=0.519), \Delta \mathrm{DBP}(p=0.591)$ or $\Delta \mathrm{HR}(p=0.339)$. No significant difference was noted for the incidence of intraoperative minimum SBP $<80 \mathrm{mmHg}(p=0.271)$, intraoperative maximum $\mathrm{SBP} \geq 160 \mathrm{mmHg}(0.306)$, intraoperative maximum SBP $\geq 220 \mathrm{mmHg}$ (0.666), intraoperative minimum HR $(p=0.756), \mathrm{MAP}<60 \mathrm{mmHg}(p=0.534)$, SBP $<70 \%$ of basic SBP $(p=0.405), \operatorname{SBP}>130 \%$ of basic SBP $(p=0.665), \mathrm{SBP} \geq 200 \mathrm{mmHg}$ or $\mathrm{MAP}<60 \mathrm{mmHg}$ $(p=0.904)$. We further stratified data on the basis of blood pressure values but did not find a statistically significant difference in the number of people with SBP 160-179 $\mathrm{mmHg}$ $(p=0.579)$, the number of people with SBP $180-199 \mathrm{mmHg}$ $(p=0.919)$, the number of people with SBP $200-219 \mathrm{mmHg}$ $(p=0.565)$, intraoperative maximum $\mathrm{SBP} \geq 180 \mathrm{mmHg}$ $(p=0.559)$, or intraoperative maximum $\mathrm{SBP} \geq 200 \mathrm{mmHg}$ ( $p=0.483)$. However, we found that group C ( $>30$ days) had a lower intraoperative minimum heart rate (HR) [group A vs. group B vs. group $\mathrm{C}=60$ (52-67) vs. 59 (50-61) vs. 51.5 $(50-58.75), p=0.024]$.

\section{Complications}

Finally, we found 47 people with 76 complications in our research. Except for one patient who died postoperatively, the remaining patients recovered well and were discharged after symptomatic treatment. These complications are summarized in Table 3.

As shown in Table 4, according to the requirement of the intensive care unit (ICU), the days in the ICU, complications, and postoperative hospitalization exhibited no significant difference $(p=0.218,0.327,0.264$, and 0.633 , respectively).

However, we found that group $\mathrm{C}$ ( $>30$ days) had the greatest incidence of postoperative hypotension requiring vasopressor support [group A vs. group B vs. group C $=14$ $(20.3 \%)$ vs. $12(27.9 \%)$ vs. $10(50.0 \%), p=0.032]$ (Table 4$)$.

\section{Discussion}

The history of preoperative medical preparation in patients with pheochromocytoma encompasses nearly 70 years [6]. Preoperative $\alpha$-adrenergic receptor blockers in patients with pheochromocytoma can not only normalize blood pressure and heart rate but also reverse catecholamine-induced blood 
Table 1 Patient and tumor characteristics

\begin{tabular}{|c|c|c|c|c|c|}
\hline & Group A & Group B & Group C & Overall & $p$ \\
\hline No. of cases, $n$ & 69 & 43 & 20 & 132 & \\
\hline Age & $46.41 \pm 13.86$ & $49.35 \pm 15.16$ & $52.50 \pm 15.55$ & $48.29 \pm 14.61$ & 0.221 \\
\hline Gender & & & & & 0.162 \\
\hline Female & $34(49.3 \%)$ & $27(62.8 \%)$ & $14(70.0 \%)$ & $75(56.8 \%)$ & \\
\hline Male & $35(50.7 \%)$ & $16(37.2 \%)$ & $6(30.0 \%)$ & $57(43.2 \%)$ & \\
\hline BMI & $23.95(20.98-26.14)$ & $23.05(21.30-25.10)$ & $22.88(20.25-24.22)$ & $23.05(21.15-25.48)$ & 0.470 \\
\hline \multicolumn{6}{|l|}{ Preoperative BP } \\
\hline SBP & $125(115-130)$ & $124(112-132)$ & $119(111-144)$ & $124(112.25-131)$ & 0.951 \\
\hline $\mathrm{DBP}$ & $78(70-81)$ & $72(68-80)$ & $72.5(67-77)$ & $75(69-80)$ & 0.063 \\
\hline Preoperative HR & $76(72-79)$ & $76(72-80)$ & $78(73-80)$ & $76(72-80)$ & 0.746 \\
\hline \multicolumn{6}{|l|}{ Preoperative $\mathrm{BP}_{\max }$} \\
\hline $\mathrm{SBP}_{\max }$ & $160(136-181)$ & $160(130-200)$ & $180(151-189)$ & $160(135-190)$ & 0.604 \\
\hline $\mathrm{DBP}_{\max }$ & $94(80-110)$ & $90(77-120)$ & $92(86-108)$ & $92(80-110)$ & 0.954 \\
\hline Surgical approach & & & & & 0.519 \\
\hline Open & $11(15.9 \%)$ & $10(23.3 \%)$ & $5(25.0 \%)$ & $26(19.7 \%)$ & \\
\hline Endoscopic & $58(84.1 \%)$ & $33(76.7 \%)$ & $15(75.0 \%)$ & $106(80.3 \%)$ & \\
\hline Size of tumor, $\mathrm{cm}$ & $5.00(4.00-6.55)$ & $5.10(3.60-6.20)$ & $4.90(4.13-6.43)$ & $5.00(4.00-6.50)$ & 0.972 \\
\hline Tumor laterality & & & & & 0.179 \\
\hline Left & $23(33.3 \%)$ & $21(48.8 \%)$ & $10(50.0 \%)$ & $54(40.9 \%)$ & \\
\hline Right & $46(66.7 \%)$ & $22(51.2 \%)$ & $10(50.0 \%)$ & $78(59.1 \%)$ & \\
\hline Biochemical positive & $50(72.5 \%)$ & $34(79.1 \%)$ & $16(80.0 \%)$ & $100(75.8 \%)$ & 0.649 \\
\hline Average dose of DOX & $4(4-4)$ & $4(4-4)$ & $4(4-8)$ & $4(4-4)$ & 0.674 \\
\hline Cases of $\beta$-blockers & $10(14.5 \%)$ & $12(27.9 \%)$ & $5(25.0 \%)$ & $27(20.5 \%)$ & 0.198 \\
\hline Cases of ACEIs & $6(8.7 \%)$ & $3(7.0 \%)$ & $0(0.0 \%)$ & $9(6.8 \%)$ & 0.565 \\
\hline Cases of ARBs & $5(7.2 \%)$ & $7(16.3 \%)$ & $2(10.0 \%)$ & $14(10.6 \%)$ & 0.339 \\
\hline Cases of CCBs & $17(24.6 \%)$ & $15(34.9 \%)$ & $5(25.0 \%)$ & $37(28.0 \%)$ & 0.476 \\
\hline
\end{tabular}

$B M I$ body mass index, $B P$ blood pressure, $S B P$ systolic blood pressure, $D B P$ diastolic blood pressure, $H R$ heart rate, $D O X$ Doxazosin (mg/day), $A C E I s$ angiotensin-converting enzyme inhibitors, $A R B s$ angiotensin receptor blockers, $C C B s$ calcium channel blockers

volume contraction preoperatively [13]. Even preoperative management has been proven to reduce the risk of intraoperative hemodynamic instability and postoperative complications $[3,6,14]$.

Since 1988, doxazosin, a selective $\alpha$-antagonist, has been widely adopted in the preoperative management of patients with pheochromocytoma [15]. Compared with nonselective $\alpha$ receptor blockers, DOX can reduce the incidence of tachycardia caused by blockage of the $\alpha 2$-adrenoceptor on the presynaptic membrane that affects norepinephrine uptake or release [16]. DOX was associated with fewer sustained postoperative hypotension events and better postoperative hemodynamic recovery than were nonselective adrenergic blockers [13]. The duration of preoperative administration of DOX was negatively correlated with the maximum intraoperative blood pressure [17]. However, the optimal duration of preoperative $\alpha 1$-selective adrenergic receptor blockers remains unclear [3], and evidence for the most appropriate duration of preoperative preparation with DOX is lacking. Currently, clinicians often rely on experience and their own institution to determine the time of preoperative medication management. Certain researchers have reported a median duration of DOX of more than 4 weeks $[5,10,18]$. The median duration of preoperative management with DOX in our center is 15 days. Different from previous studies on the definition of time of preoperative management, our research defined the duration as the time between final dose adjustment and surgery.

Our result indicated that preoperative management of pheochromocytoma with single $\alpha$-receptor blocker DOX more than 1 month after the final dose adjustment could lead to intraoperative bradycardia, which was not reported in previous studies. Two studies showed that the duration of preoperative management does not influence intraoperative hemodynamic fluctuations and postoperative complications. Russell [19] et al. found that the duration of preoperative management is not related to the stability of surgery. However, the sample size in that study was only 14 people, the evaluation index for stable operation was simple, and the longest medication time was no more than 15 days. Hack 
Table 2 Intraoperative hemodynamics of the three groups

\begin{tabular}{|c|c|c|c|c|c|}
\hline & Group A & Group B & Group C & Overall & $p$ \\
\hline Intraoperative $\mathrm{SBP}_{\min }$ & $90(82-100)$ & $96(90-102)$ & $90(76-103)$ & $90(84-100)$ & 0.260 \\
\hline Intraoperative $\mathrm{DBP}_{\min }$ & $50(46-60)$ & $55(48-60)$ & $50(43-59)$ & $50(46-60)$ & 0.300 \\
\hline $\mathrm{SBP}<80 \mathrm{mmHg}, n$ & $9(13.0 \%)$ & $4(9.3 \%)$ & $5(25.0 \%)$ & $18(13.6 \%)$ & 0.271 \\
\hline $\mathrm{SBP} \geq 160 \mathrm{mmHg}, n$ & $45(65.2 \%)$ & $30(69.8 \%)$ & $10(50.0 \%)$ & $85(64.4 \%)$ & 0.306 \\
\hline $160 \mathrm{mmHg} \leq \mathrm{SBP}<180 \mathrm{mmHg}, n$ & $22(31.9 \%)$ & $12(27.9 \%)$ & $4(20.0 \%)$ & $38(28.8 \%)$ & 0.579 \\
\hline $\mathrm{SBP} \geq 180 \mathrm{mmHg}, n$ & $23(33.3 \%)$ & $18(41.9 \%)$ & $6(30.0 \%)$ & $47(35.6 \%)$ & 0.559 \\
\hline $180 \mathrm{mmHg} \leq \mathrm{BP}<200 \mathrm{mmHg}, n$ & $13(18.8 \%)$ & $8(18.6 \%)$ & $3(15.0 \%)$ & $24(18.2 \%)$ & 0.919 \\
\hline $\mathrm{SBP} \geq 200 \mathrm{mmHg}, n$ & $10(14.5 \%)$ & $10(23.3 \%)$ & $3(15.0 \%)$ & $23(17.4 \%)$ & 0.483 \\
\hline $200 \mathrm{mmHg} \leq \mathrm{SBP}<220 \mathrm{mmHg}, n$ & $6(8.7 \%)$ & $6(14.0 \%)$ & $1(5.0 \%)$ & $13(9.8 \%)$ & 0.565 \\
\hline $\mathrm{SBP} \geq 220 \mathrm{mmHg}, n$ & $4(5.8 \%)$ & $4(9.3 \%)$ & $2(10.0 \%)$ & $10(7.6 \%)$ & 0.666 \\
\hline$<70 \%$ of basic SBP & $24(34.8 \%)$ & $12(27.9 \%)$ & $9(45.0 \%)$ & $45(34.1 \%)$ & 0.405 \\
\hline$>130 \%$ of basic SBP & $39(56.5 \%)$ & $28(65.1 \%)$ & $12(60.0 \%)$ & $79(59.8 \%)$ & 0.665 \\
\hline Intraoperative $\mathrm{SBP}_{\max }$ & $170(149-183)$ & $170(150-198)$ & $159(145-180)$ & $170(150-188)$ & 0.222 \\
\hline Intraoperative $\mathrm{DBP}_{\max }$ & $90(80-105)$ & $99(90-102)$ & $89(76-100)$ & $91(84-101.5)$ & 0.091 \\
\hline Intraoperative $\mathrm{HR}_{\max }$ & $90(80-101.5)$ & $91(80-100)$ & $86(71-108)$ & $90(79-101)$ & 0.756 \\
\hline Intraoperative $\mathrm{HR}_{\min }$ & $60(52-67)$ & $59(50-61)$ & $52(50-59)$ & $59(50-61)$ & $0.024^{*}$ \\
\hline $\mathrm{MAP}<60$ & $17(24.6 \%)$ & $7(16.3 \%)$ & $5(25.0 \%)$ & $29(22.0 \%)$ & 0.534 \\
\hline$\triangle \mathrm{SBP}$ & $71(55-92)$ & $79(60-105)$ & $75(50-101)$ & $75(57-95)$ & 0.519 \\
\hline$\triangle \mathrm{DBP}$ & $40(30-50)$ & $40(31-57)$ & $39(27-53.5)$ & $40(30-53)$ & 0.591 \\
\hline$\Delta \mathrm{HR}$ & $30(20-40)$ & $34(24-46)$ & $34(20-48)$ & $31(20-44)$ & 0.339 \\
\hline $\mathrm{SBP} \geq 200 \mathrm{mmHg}$ and/or $\mathrm{MAP}<60 \mathrm{mmHg}$ & $24(34.8 \%)$ & $16(37.2 \%)$ & $8(40.0 \%)$ & $48(36.4 \%)$ & 0.904 \\
\hline
\end{tabular}

$\triangle \mathrm{SBP}=\mathrm{SBP}_{\max }-\mathrm{SBPmin} ; \Delta \mathrm{DBP}=\mathrm{DBP}_{\max }-\mathrm{DBP}_{\min } ; \Delta \mathrm{HR}=\mathrm{HR}_{\max }-\mathrm{HR}_{\min }$

$S B P_{\min }$, minimum systolic blood pressure, $S B P_{\max }$ maximum systolic blood pressure, $D B P_{\min }$ minimum diastolic blood pressure, $D B P_{\max }$ maximum diastolic diastolic blood pressure, $H R_{\max }$ maximum heart rate, $M A P$ mean arterial pressure

*Statistically significant

Table 3 Summary of postoperative complications base on the relationship with hemodynamics

\begin{tabular}{ll}
\hline Variable & $\begin{array}{l}\text { All complica- } \\
\text { tions } n=76\end{array}$ \\
\hline Directly related to hemodynamic stability & 3 \\
New arrhythmia & 36 \\
Postoperative hypotension and use of vasopressor & \\
Not directly related to hemodynamic stability & 5 \\
Pulmonary complications & 2 \\
Postoperative bleeding & 1 \\
Postoperative intestinal obstruction & 7 \\
Acute liver injury after the operation & 6 \\
Postoperative acute kidney injury & 2 \\
Venous thrombosis & 2 \\
Hypoglycemia & 1 \\
Death & \\
\hline
\end{tabular}

et al. reached a similar conclusion, but the study was limited in focusing only on young patients and having a small sample size [20]. The effect on HR was not reported in these studies. Although the $\alpha 1$-blocker has a limited impact on HR theoretically, our study demonstrated that long-term administration might significantly reduce HR and might increase intraoperative risk. However, the reason why prolonging the duration of preoperative treatment with the $\alpha 1$-selective adrenoceptor blocker doxazosin (DOX) will affect the heart rate of surgery needs further research.

Our results also show that patients with DOX preoperative medication for more than 1 month after the final dose adjustment have a greater incidence of postoperative hypotension requiring vasopressor support. Reese [5] et al. demonstrated that DOX causes more cases of $\mathrm{SBP}<80$ than PXB in 52 patients with pheochromocytoma undergoing laparoscopic surgery. Furthermore, postoperatively, the DOX group requires more additional support with vasopressor infusions under PACU or ICU admission. However, no significant differences in postoperative discharge time were observed between the 3 groups. It should be noted that compared with that from PXB data [11], the proportion of postoperative hypotension was relatively low, which was generally in accordance with the findings of previous reports on the difference between DOX and PXB. Nevertheless, long-term administration of DOX could also relatively increase this risk. 
Table 4 The major postoperative outcome of the three groups

\begin{tabular}{lccccc}
\hline & Group A & Group B & Group C & Overall & $p$ \\
\hline Cases of ICU needed, $n$ & $42(60.9 \%)$ & $25(58.1 \%)$ & $16(80.0 \%)$ & $83(62.9 \%)$ & 0.218 \\
ICU, day & $1(0-1)$ & $1(0-1)$ & $1(1-1)$ & $1(0-1)$ & 0.327 \\
Postoperative hypotension and & $14(20.3 \%)$ & $12(27.9 \%)$ & $10(50.0 \%)$ & $36(27.3 \%)$ & $0.0328^{*}$ \\
$\quad$ vasopressor support, $n$ & & & & & \\
Complications, $n$ & $21(30.4 \%)$ & $16(37.2 \%)$ & $10(50.0 \%)$ & $47(35.6 \%)$ & 0.264 \\
Postoperative hospitalization, day & $5.0(3.5-7.0)$ & $5.0(4.0-7.0)$ & $5.0(3.3-7.0)$ & $5.0(4.0-7.0)$ & 0.633 \\
\hline
\end{tabular}

$I C U$ intensive care unit

*Statistically significant
In our study, the clinical characteristics, catecholamine test results, and surgical approaches were comparable among the three groups, and we found no significant differences in preoperative hemodynamics or medication management. All of these observations make our conclusion more reliable, proving that a longer duration of DOX not only confers no benefit in terms of perioperative hemodynamics but also might lead to a higher risk of postoperative hemodynamic stability-related complications.

There are certain limitations to this study. First, this study represents a retrospective review of data at a single center, which might incur selective and recall bias, and further external validation (especially in non-Chinese cohorts) is necessary. Second, since 2016, we have performed metanephrine testing for patients with suspected pheochromocytoma. Therefore, of the 132 patients in this group, only 25 underwent metanephrine testing. Although all patients were positive in the metanephrine test, this index could not be included in the risk factor analysis. Finally, a large sample of prospective randomized controlled studies is needed to further verify the conclusion.

\section{Conclusion}

The current study indicated that the preoperative management of pheochromocytoma with single $\alpha$-receptor blocker DOX for more than 30 days after final dose adjustment might lead to intraoperative bradycardia and a heightened incidence of postoperative hypotension requiring vasopressor support. Thus, our study does not support long-term (over 30 days) preoperative administration of pheochromocytoma with single $\alpha$-receptor blocker DOX in the final dose.

Acknowledgments The authors thank the entire staff of the Department of Anaesthesiology, Endocrinology, Clinical Laboratory and Urology, Peking University First Hospital.

Author contributions Study concept and design: Z.Z., D.F. and J.Z. Data extraction and analysis: H.K., N.L., J.T., L.L, K.W., Y.G. and B.J. Manuscript drafting: H.K., N.L., and J.T. Manuscript revision: H.K., N.L., and J.T. Manuscript review and editing: Z.Z., D.F., J.Z. and L.Z
Funding This study was funded by the PUHSC Clinical Research Project (PUCRP201302), the Interdisciplinary Medicine Seed Fund of Peking University (BMU2018MX026), the Interdisciplinary Clinical Research Project of Peking University First Hospital (2019CR33) and Scientific Research Seed Fund of Peking University First Hospital (2018SF066).

\section{Compliance with ethical standard}

Conflict of interest The authors declare that there are no conflicting interests.

Open Access This article is licensed under a Creative Commons Attribution 4.0 International License, which permits use, sharing, adaptation, distribution and reproduction in any medium or format, as long as you give appropriate credit to the original author(s) and the source, provide a link to the Creative Commons licence, and indicate if changes were made. The images or other third party material in this article are included in the article's Creative Commons licence, unless indicated otherwise in a credit line to the material. If material is not included in the article's Creative Commons licence and your intended use is not permitted by statutory regulation or exceeds the permitted use, you will need to obtain permission directly from the copyright holder. To view a copy of this licence, visit http://creativecommons.org/licenses/by/4.0/.

\section{References}

1. Liu C, Lv Q, Chen X, Ni G, Hu L, Tong N, Zhang Y (2017) Preoperative selective vs non-selective alpha-blockade in PPGL patients undergoing adrenalectomy. Endocr Connect 6(8):830-838. https ://doi.org/10.1530/EC-17-0232

2. Lenders JWM, Eisenhofer G, Mannelli M, Pacak K (2005) Phaeochromocytoma Lancet 366(9486):665-675. https://doi. org/10.1016/s0140-6736(05)67139-5

3. Challis BG, Casey RT, Simpson HL, Gurnell M (2017) Is there an optimal preoperative management strategy for phaeochromocytoma/paraganglioma? Clin Endocrinol (Oxf) 86(2):163-167. https://doi.org/10.1111/cen.13252

4. Costa Almeida CE, Silva M, Carvalho L, Costa Almeida CM (2017) Adrenal giant cystic pheochromocytoma treated by posterior retroperitoneoscopic adrenalectomy. Intern J Surg Case Rep 30:201-204. https://doi.org/10.1016/j.ijscr.2016.12.018

5. Randle RW, Balentine CJ, Pitt SC, Schneider DF, Sippel RS (2017) Selective versus non-selective alpha-blockade prior to laparoscopic adrenalectomy for pheochromocytoma. Ann Surg Oncol 24(1):244-250. https://doi.org/10.1245/s10434-016-5514-7 
6. Brunaud L, Nguyen-Thi PL, Mirallie E, Raffaelli M, Vriens M, Theveniaud PE, Boutami M, Finnerty BM, Vorselaars WMCM, Rinkes IB (2016) Predictive factors for postoperative morbidity after laparoscopic adrenalectomy for pheochromocytoma: a multicenter retrospective analysis in 225 patients. Surg Endosc 30(3):1051-1059. https://doi.org/10.1007/s00464-015-4294-7

7. Bruynzeel H, Feelders RA, Groenland TH, Ah VDM, van Eijck CH, Lange JF, de Herder WW, Kazemier G (2010) Risk factors for hemodynamic instability during surgery for pheochromocytoma. J Clin Endocr Metab 95(2):678-685. https://doi.org/10.1210/ jc. 2009-1051

8. Goldstein RE, O'Neill JA Jr, Holcomb GW 3rd, Morgan WM 3rd, Neblett WW 3rd, Oates JA, Brown N, Nadeau J, Smith B, Page DL, Abumrad NN, Scott HW Jr (1999) Clinical experience over 48 years with pheochromocytoma. Ann Surg 229(6):755-764

9. Lenders JW, Duh QY, Eisenhofer G, Gimenez-Roqueplo AP, Grebe SK, Murad MH, Naruse M, Pacak K, Young WF Jr, Endocrine S (2014) Pheochromocytoma and paraganglioma: an endocrine society clinical practice guideline. J Clin Endocrinol Metab 99(6):1915-1942. https://doi.org/10.1210/jc.2014-1498

10. Kocak S, Aydintug S, Canakci N (2002) Alpha blockade in preoperative preparation of patients with pheochromocytomas. Int Surg 87(3):191-194

11. Tian J, Bao Z, Yuan Y, Fang D, Zhan Y, Wang T, Zhang Z, Liqun $Z$ (2019) The duration of preoperative administration of single -receptor blocker phenoxybenzamine before adrenalectomy for pheochromocytoma: 18 years of clinical experience from nationwide high-volume center. Biomed Res Int 2019:2613137. https:// doi.org/10.1155/2019/2613137

12. Katayama H, Kurokawa Y, Nakamura K, Ito H, Kanemitsu Y, Masuda N, Tsubosa Y, Satoh T, Yokomizo A, Fukuda H, Sasako M (2016) Extended Clavien-Dindo classification of surgical complications: Japan Clinical Oncology Group postoperative complications criteria. Surg Today 46(6):668-685. https://doi. org/10.1007/s00595-015-1236-x

13. Kiernan CM, Du L, Chen X, Broome JT, Shi C, Peters MF, Solorzano CC (2014) Predictors of hemodynamic instability during surgery for pheochromocytoma. Ann Surg Oncol 21(12):38653871. https://doi.org/10.1245/s10434-014-3847-7

14. van der Zee PA, de Boer A (2014) Pheochromocytoma: a review on preoperative treatment with phenoxybenzamine or doxazosin. Neth J Med 72(4):190-201

15. Miura Y, Yoshinaga K (1989) Doxazosin: a newly developed, selective $\alpha 1$-inhibitor in the management of patients with pheochromocytoma. Am Heart J 116(6 Pt 2):1785-1789

16. Prys-Roberts C, Farndon JR (2002) Efficacy and safety of doxazosin for perioperative management of patients with pheochromocytoma. World J Surg 26(8):1037-1042. https://doi.org/10.1007/ s00268-002-6667-z

17. Malec K, Miskiewicz P, Witkowska A, Krajewska E, Toutounchi S, Galazka Z, Piotrowski M, Kacka A, Bednarczuk T, Ambroziak U (2017) Comparison of phenoxybenzamine and doxazosin in perioperative management of patients with pheochromocytoma. Kardiol Pol 75(11):1192-1198. https://doi.org/10.5603/KP.a2017 .0147

18. Falhammar H, Kjellman M, Calissendorff J (2018) Treatment and outcomes in pheochromocytomas and paragangliomas: a study of 110 cases from a single center. Endocrine 62(3):566-575. https:// doi.org/10.1007/s12020-018-1734-X

19. Russell WJ, Metcalfe IR, Tonkin AL, Frewin DB (1998) The preoperative management of phaeochromocytoma. Anaesth Intensive Care 26(2): 196-200

20. Hack HA, Brown TC (1999) Preoperative management of phaeochromocytoma - a paediatric perspective. Anaesth Intensive Care 27(1):112-113

Publisher's Note Springer Nature remains neutral with regard to jurisdictional claims in published maps and institutional affiliations. 